\title{
O SENTIDO DO JOGO NA EDUCAÇÃO INFANTIL E NO ENSINO FUNDAMENTAL: UMA ANÁLISE ACERCA DA BASE NACIONAL COMUM CURRICULAR
}

\author{
THE SENSE OF PLAY IN CHILDREN EDUCATION AND FUNDAMENTAL EDUCATION: AN \\ ANALYSIS ABOUT THE NATIONAL COMMON CURRICULUM BASIS \\ EL SENTIDO DEL JUEGO EN LA EDUCACIÓN INFANTIL Y EN LA ENSEÑANZA \\ FUNDAMENTAL: UN ANÁLISIS ACERCA DE LA BASE NACIONAL COMÚN CURRICULAR
}

Claube Camile Soares Lima E-mail: cacaulima2009@yahoo.com.br

João Francisco Magno Ribas E-mail: ribasjfm@hotmail.com

Raquel Valente de Oliveira E-mail: raquelvvallente@hotmail.com

Universidade Federal de Santa Maria (UFSM)

\section{RESUMO}

Essa pesquisa objetivou identificar o sentido do Jogo disposto na Base Nacional Comum Curricular (BNCC), na Educação Infantil e nos distintos componentes curriculares do Ensino Fundamental - anos iniciais e anos finais. Para isso, realizou-se uma análise documental, de caráter qualitativo, por meio da qual constatou-se que na Educação Infantil o Jogo é tido como eixo estruturante para o desenvolvimento das aprendizagens e habilidades das crianças, devendo ser trabalhado no decorrer de toda essa etapa de ensino. Já no Ensino Fundamental, dependendo do componente curricular, o mesmo apresenta-se como um conteúdo com fim em si mesmo, como na Educação Física e na Arte; como meio (metodologia) para ensinar os conteúdos específicos de cada disciplina, estando presente nas habilidades a serem por elas desenvolvidas (Língua Portuguesa, Língua Inglesa, Geografia, História e Ensino Religioso); ou ainda encontra-se ausente, assim como na Matemática e nas Ciências. Desse modo, a cultura do Jogo, enquanto construção social, precisa ser vivenciada em um determinado tempo e espaço, levando em consideração sua importância no desenvolvimento do indivíduo durante a infância e a adolescência, ancorado por documentos de caráter educacional como a BNCC, na qual determina, norteia e orienta as práticas pedagógicas da Educação Básica.

PALAVRAS-CHAVE: Jogo. Base Nacional Comum Curricular. Educação Infantil. Ensino Fundamental.

\section{ABSTRACT}

The purpose of this research was to identify the meaning of the Game, which is based on the National Common Curriculum Basis (BNCC), on Early Childhood Education and on the different curricular components of Fundamental Education - initial years and final years. For this, a qualitative documentary analysis was carried out, through which it was verified that in Childhood Education, the Game is considered as a structuring axis for the development of children's learning and skills, and it should be worked through teaching stage. In Fundamental Education, depending on the curricular component, it presents itself as content with an end in itself, as in Physical Education and Art; as a means (methodology) to teach the specific contents of each subject, being present in the skills to be developed by them (Portuguese Language, English Language, Geography, History and Religious Education); or is still absent, as well as in Mathematics and Science. Thus, the culture of the Game, as a social construction, needs to be experienced in a certain time and space, taking into account its importance in the development of the individual during childhood and adolescence, anchored by educational documents such as BNCC, in which determines, guides and guides the pedagogical practices of Basic Education.

KEYWORDS: Game. National Common Curriculum Basis. Childhood Education. Fundamental Education. 


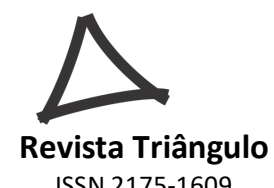

ISSN 2175-1609

\section{RESUMEN}

Esta investigación objetivó identificar el sentido del Juego dispuesto en la Base Nacional Común Curricular $(B N C C)$, en la Educación Infantil y en los distintos componentes curriculares de la Enseñanza Fundamental años iniciales y años finales. Para ello, se realizó un análisis documental, de carácter cualitativo, por medio de la cual se constató que en la Educación Infantil el Juego es tenido como eje estructurante para el desarrollo de los aprendizajes y habilidades de los niños, debiendo ser trabajado en el transcurso de toda esa etapa de enseñanza. En la Enseñanza Fundamental, dependiendo del componente curricular, el mismo se presenta como un contenido con fin en sí mismo, como en la Educación Física y en el Arte; como (metodología) para enseñar el contenido especifico de cada disciplina, estando presente en las habilidades a desarrollar por ellos (Lengua Portuguesa, Inglés Lengua, Geografía, Historia y educación religiosa); o aún se encuentra ausente, así como en la Matemática y en las Ciencias. De este modo, la cultura del Juego, como construcción social, necesita ser vivenciada en un determinado tiempo y espacio, teniendo en cuenta su importancia en el desarrollo del individuo durante la infancia y la adolescencia, anclado por documentos de carácter educativo como la BNCC, en la cual determina, orienta y orienta las prácticas pedagógicas de la Educación Básica.

PALABRAS-CLAVE: Juego. Base Nacional Común Curricular. Educación Infantil. Enseñanza Fundamental.

\section{INTRODUÇÃO}

Ao se pensar na qualidade e em melhorias para a educação brasileira, iniciou-se o processo de construção democrática de um novo documento educacional que envolveu vários educadores e profissionais da área. Com essa ação, se consolidou, em 2018, pelo Ministério da Educação, a Base Nacional Comum Curricular (BNCC), com o objetivo de nortear e orientar a elaboração dos currículos e das propostas pedagógicas de instituições públicas e privadas da Educação Básica, políticas para formação de professores, materiais didáticos e avaliações.

Portanto, a Base Nacional Comum Curricular caracteriza-se por um conjunto de aprendizagens essenciais para que todos os alunos tenham direito à Educação Básica. Esse documento coloca a educação brasileira no centro do processo. Para chegar ao produto final da BNCC já se faziam debates desde a Constituição de 1988, na qual destacava a educação a serviço do pleno desenvolvimento da pessoa, do preparo para o exercício da cidadania e da qualificação para o trabalho (BRASIL, 1988). A seguir, ilustra-se como está organizada, politicamente, a Base Nacional Comum Curricular.

Figura 1 - Estrutura Política da Base Nacional Comum Curricular. 


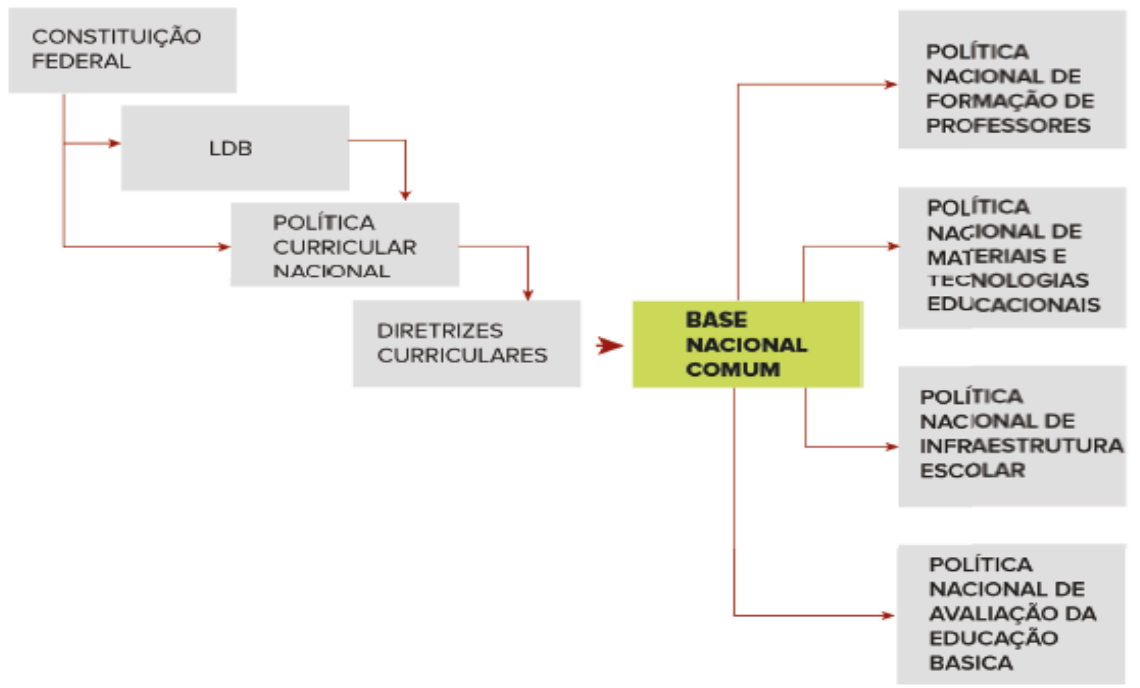

Fonte: Brasil (2016, p. 26).

Sendo assim, a BNCC representa um instrumento para a promoção da equidade, isto é, igualdade de direitos educacionais para todos no país, a medida em que define as aprendizagens essenciais e orienta as políticas educacionais que serão implementadas nas escolas brasileiras com um papel decisivo na formação integral do cidadão (BRASIL, 2018). Esse documento surgi com a possibilidade de aproximar as diferentes realidades e um consenso essencial comum para que os alunos se aproximem ao máximo da aprendizagem mínima exigida para cada nível e área de estudo na Educação Básica Nacional. Além disso, a BNCC apresenta finalidades e diálogos com outras políticas públicas, entre elas a formação de professores, buscando relacioná-la com os demais documentos legais, livros didáticos, dentre outros.

Desse modo, o referido documento vem com o objetivo de situar e orientar instituições e professores com conteúdos mínimos comuns de ensino, com uma parte diferencial que é elaborada pelos estados e municípios ao considerar as diversidades e peculiaridades de cada indivíduo em sua determinada região. Ou seja, não anula dos currículos a parte específica de cada local, mas contribui no sentido de indicar oportunidades essenciais de ensino e aprendizagem para todos os brasileiros. Portanto, ela visa garantir os conteúdos disciplinares comuns a serem trabalhados em todas as escolas brasileiras da Educação Infantil ao Ensino Médio (BRASIL, 2018).

Silva, Guimarães e Medeiros (2018, p. 170) corroboram com isso ao complementar que: 
No documento, idealiza-se que os alunos matriculados em todas as escolas de ensino básico, nas cinco regiões geográficas brasileiras, tenham acesso aos mesmos componentes curriculares (disciplinas escolares), a partir da indicação de objetos de conhecimento (conteúdos disciplinares) e de habilidades a serem trabalhadas ao longo da escolaridade.

Já no que diz respeito a sua estrutura, a mesma apresenta as etapas da Educação Básica, as competências gerais e específicas, as áreas de conhecimento com seus respectivos componentes curriculares, bem como seus objetivos e habilidades. Na figura abaixo, ilustra-se a referida estrutura desse documento, em que se optou por destacar somente as etapas da Educação Infantil e Ensino Fundamental por serem o foco desta pesquisa.

Figura 2 - Estrutura Geral da Base Nacional Comum Curricular.

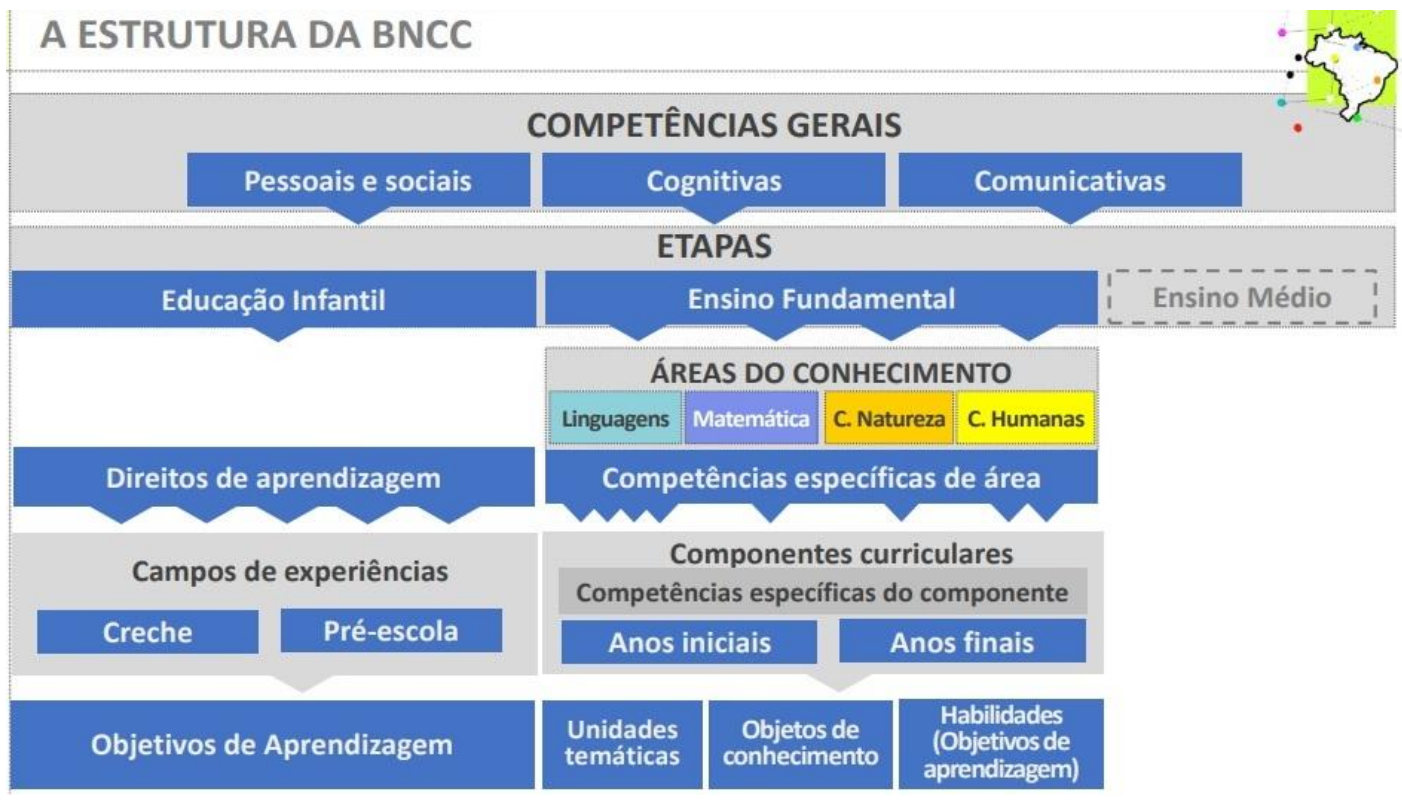

Fonte: Adaptada de Brasil (2017, p. 5).

Como um dos conhecimentos presentes na BNCC, o Jogo caracteriza-se como um dos conteúdos pertencentes à Educação Física. No entanto, essa manifestação cultural também pode ocupar um lugar, seja ele primário ou secundário, nas demais disciplinas escolares. Além disso, pode-se afirmar que o Jogo é expressivamente peculiar da Educação Infantil, uma vez que ele está naturalmente presente na infância, podendo se estender as demais fases da vida. Para Huizinga (2007, p. 33), o Jogo é "uma atividade ou ocupação voluntária, exercida dentro de certos e determinados limites de tempo e espaço, segundo regras livremente consentidas, mas absolutamente obrigatórias, dotado de um fim em si mesmo". 


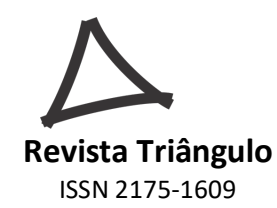

Ao compreender o Jogo e valorizá-lo como um dos conteúdos que constitui o currículo escolar, cada vez mais se estará incentivando-o nesse contexto, para que sua prática não seja diminuída por motivos de espaço e tempo, o que deixariam as crianças, bem como os jovens, distantes de vivenciar e experimentar as variadas brincadeiras e Jogos. Indo ao encontro disso, Kunz (2017, p. 62) discorre sobre essa manifestação cultural no contexto da Educação Física, disciplina que integra expressivamente o conteúdo Jogo em seu currículo:

o brincar livre e espontâneo deve ser um conteúdo a ser seguido e valorizado [...]. O brincar assume aqui o centro de um pensar a Pedagogia para as crianças, pois se brinca quando se vive o presente, e a Educação Física destaca-se neste contexto por preocupar-se com o maior desejo expressivo da criança, seu movimento/brincadeira.

Sendo assim, tem-se como problemática da pesquisa: Como o conhecimento Jogo é abordado pela Base Nacional Comum Curricular nas diferentes disciplinas escolares durante a Educação Infantil e o Ensino Fundamental? Logo, o objetivo deste estudo consiste em identificar o sentido do Jogo disposto na Base Nacional Comum Curricular, na Educação Infantil e nos distintos componentes curriculares do Ensino Fundamental - anos iniciais e anos finais.

\section{METODOLOGIA}

Para alcançar o objetivo proposta pela pesquisa, realizou-se uma Análise Documental acerca do sentido/significado do Jogo presente na Base Nacional Comum Curricular. Esse tipo de pesquisa se caracteriza pela utilização de documentos, objetivando descrever ou comparar fatos sociais, estabelecendo suas próprias características e tendências, conforme os objetivos previamente determinados (PIMENTEL, 2001). Sendo assim, conforme Sá-Silva, Almeida e Guindani (2009, p. 4), a Análise Documental, como metodologia de pesquisa, é quando:

um pesquisador utiliza documentos objetivando extrair dele informações, ele o faz investigando, examinando, usando técnicas apropriadas para seu manuseio e análise; segue etapas e procedimentos; organiza informações a serem categorizadas e posteriormente analisadas; por fim, elabora sínteses, ou seja, na realidade, as ações dos investigadores - cujos objetos são documentos - estão impregnadas de aspectos metodológicos, técnicos e analíticos.

Logo, apoiou-se em análise de pesquisa qualitativa, cujo intuito é conhecer e evidenciar os conhecimentos científicos sobre o tema do estudo, publicado em um documento oficial. Nessa perspectiva, Richardson (1999, p. 102) destaca que o objetivo da pesquisa qualitativa "não reside na produção de opiniões representativas e objetivamente mensuráveis 
de um grupo; está no aprofundamento da compreensão de um fenômeno social por meio de análises qualitativas".

Portanto, buscou-se na Base Nacional Comum Curricular identificar o sentido do Jogo como proposta educacional nas etapas da Educação Infantil e Ensino Fundamental (anos iniciais e finais), presentes não apenas na Educação Física, mas também nos demais componentes curriculares sistematizados no referido documento - Língua Portuguesa, Arte, Língua Inglesa, Matemática, Ciências, Geografia, História e Ensino Religioso. Após o levantamento, foram realizados os apontamentos e as interpretações necessárias para análise e discussão dos dados coletados na BNCC.

\section{ANÁLISE DOS DADOS E RESULTADOS}

Tendo em vista que a pesquisa visou identificar o sentido/significado do Jogo na Educação Infantil e no Ensino Fundamental, os resultados serão apresentados seguindo essa mesma sequência. Desse modo, no que tange à Educação Infantil, essa caracteriza-se como a primeira etapa da Educação Básica e, de acordo com os eixos estruturantes desse nível de ensino (Interações e Brincadeiras), a mesma deve assegurar seis direitos de aprendizagem e desenvolvimento às crianças: conviver, brincar, participar, explorar, expressar e conhecer-se (BRASIL, 2018). Historicamente, a criança vem conquistando um importante lugar na sociedade, pois além de deveres, ela também possui direitos que foram sendo construídos gradativamente, bem como reconhecimento e valores perante a educação. Logo, a BNCC (2018, p. 35) complementa que "a interação durante o brincar caracteriza o cotidiano da infância, trazendo consigo muitas aprendizagens e potenciais para o desenvolvimento integral das crianças".

Desse modo, a Educação Infantil está organizada na BNCC de acordo com a figura abaixo.

Figura 3 - Educação Infantil e sua Estrutura. 


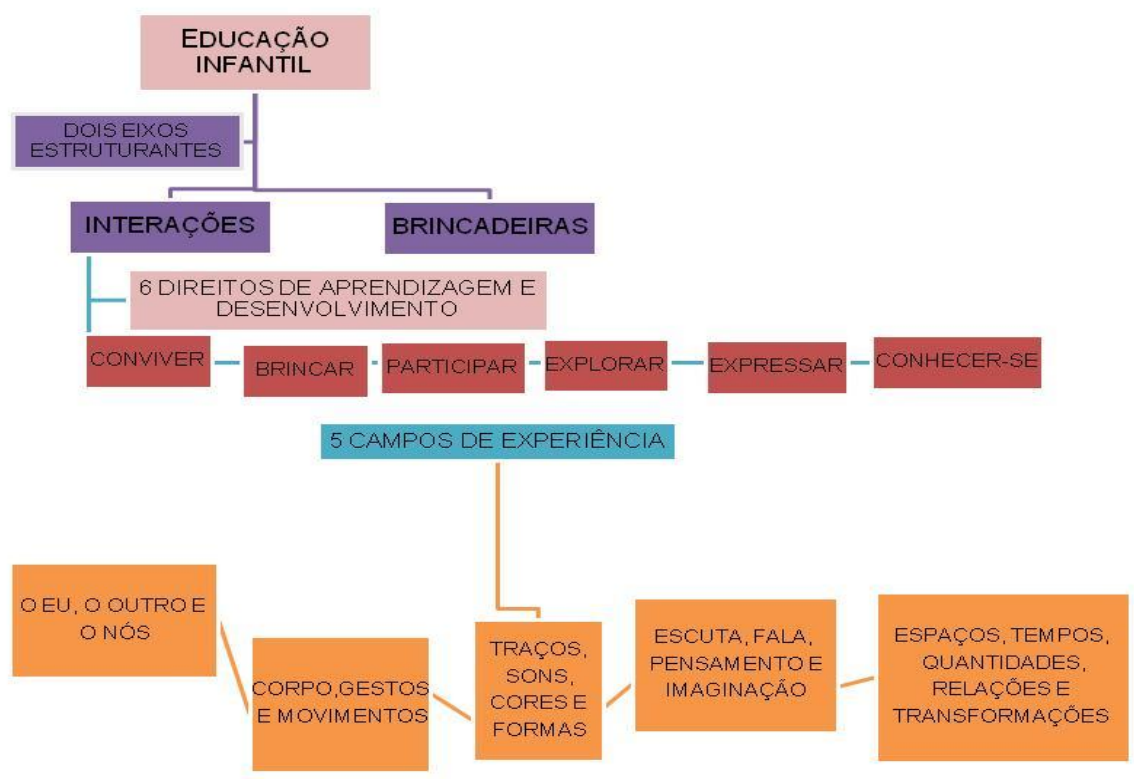

Fonte: Elaborada pelos autores.

Conforme o exposto, a BNCC destaca o brincar que é um dos eixos e direitos no âmbito de aprendizagem e desenvolvimento da criança, pois quando ela se expressa e interage durante o brincar/jogar, ela estará se comunicando de diferentes maneiras, envolvendo o corpo, a emoção e a linguagem. A Educação Infantil é a base da formação do indivíduo, bem como a etapa fundamental para que a criança se aproprie de variadas situações. Assim, ao proporcionar atividades que envolvam o Jogo e o brincar, a criança constrói conhecimentos por meio de experiências diversificadas. Corroborando com isso, Tezani $(2006$, p. 5) afirma que as ideias de Vygotsky são valiosas para o professor que desenvolve seu trabalho na Educação Infantil, ao intensificar, mediar e apoiar o brincar/jogar de forma adequada para o desenvolvimento da criança, sendo "o caminho que o indivíduo vai percorrer para desenvolver funções que estão em processos de amadurecimento e que se tornarão funções consolidadas".

A criatividade tem presença nas atividades em que um livre "se-movimentar" acontece, exemplarmente com as atividades de brincar e jogar (KUNZ, 2017). É papel do professor proporcionar momentos de interação e brincadeiras, assegurando condições para que as crianças se desenvolvam, aprendam e saibam resolver problemas e pequenos conflitos (BRASIL, 2018). A partir dos direitos de aprendizagem e desenvolvimento, a BNCC assegura na Educação Infantil as condições para que as crianças aprendam em situações nas quais 
possam desempenhar um papel ativo em ambientes que as convidem a vivenciar desafios e a sentirem-se provocadas a resolvê-los, para construir significados sobre si, sobre os outros e sobre o mundo social e natural.

Por conseguinte, com relação aos campos de experiências, onde estão definidos os objetivos de aprendizagem e desenvolvimento, constata-se que a palavra "Jogo" não é mencionada nessa parte pontual do documento. Todavia, ela está expressivamente implícita nos conceitos de cada direito de aprendizagem e desenvolvimento. Além disso, o Jogo é tido como eixo estruturante para o desenvolvimento das aprendizagens e habilidades na Educação Infantil, uma vez que ao se pensar atividades que envolvam o brincar, interpreta-se que o participante que brinca ao mesmo tempo joga (BRASIL, 2018). Isso justifica-se a medida em que o brincar/jogar, ao fazer parte da vida da criança, é apontado pelo documento como centro do processo de ensino e aprendizagem, devendo ser trabalhado no decorrer de toda a Educação Infantil.

Além da Educação Infantil, a BNCC também apresenta a organização curricular do Ensino Fundamental, que leva em consideração aspectos tanto da aprendizagem quanto do desenvolvimento educacional, estando dividido em anos iniciais e anos finais, atendendo crianças de 06 a 14 anos de idade, com duração de nove anos (BRASIL, 2018). Nessa etapa, o documento apresenta áreas de conhecimento, nas quais contém competências para todos seus respectivos componentes curriculares.

Com isso, a área de Linguagens é composta pelos seguintes componentes curriculares: Língua Portuguesa, Arte, Educação Física e, nos anos finais, também a Língua Inglesa. A área das Linguagens deve garantir aos alunos o desenvolvimento de competências específicas em articulação com as competências de cada disciplina que a compõe.

Dentro do componente Língua Portuguesa, observa-se que na $\operatorname{BNCC}(2018$, p. 71) o Jogo aparece na Dialogia e relação entre textos, como uma das habilidade a ser desenvolvida no processo educacional: "Estabelecer relações de intertextualidade e interdiscursividade que permitam a identificação e compreensão dos diferentes posicionamentos e/ou perspectivas em jogo, do papel da paráfrase e de produções como as paródias e a estilizações".

Por outro lado, em relação à produção textual, o Jogo aparece com um significado diferente ao tema proposto por este estudo. Ele está entre as habilidades de construção das relações referenciais do texto a serem desenvolvidas e compostas na seguinte dimensão: construção da textualidade, com sentido de colocar em "jogo", isto é, estabelecer relações na produção textual. Isso pode ser evidenciado em um dos trechos da BNCC (2018, p. 75): 
"Organizar e/ou hierarquizar informações, tendo em vista as condições de produção e as relações lógicas discursivas em jogo: causa/efeito; tese/argumentos; problema/solução; definição/exemplos".

Assim, destaca-se que o Jogo está presente nas habilidades a serem desenvolvidas na Língua Portuguesa, sendo citado no documento como uma das práticas no processo de alfabetização no Ensino Fundamental. Além disso, ele aparece como "jogos de palavras", na perspectiva de utilizar o Jogo como um meio de ensinar palavras necessárias a aprendizagem dos alunos, dependendo do nível em que se encontram.

No que se refere ao componente curricular Arte, tem-se as seguintes linguagens: as Artes visuais, a Dança, a Música e o Teatro. Conforme a citação da BNCC (2018, p. 201), observa-se que o Jogo está presente nesse componente nos anos iniciais, ao se tratar de suas habilidades específicas.

Perceber e explorar os elementos constitutivos da música (altura, intensidade, timbre, melodia, ritmo etc.), por meio de jogos, brincadeiras, canções e práticas diversas decomposição/criação, execução e apreciação musical.

Caracterizar e experimentar brinquedos, brincadeiras, jogos, danças, canções e histórias de diferentes matrizes estéticas e culturais.

Explorar diferentes tecnologias e recursos digitais (multimeios, animações, jogos eletrônicos, gravações em áudio e vídeo, fotografia, softwares etc.) nos processos de criação artística.

Já nos anos finais, o Jogo está presente em duas habilidades dentro do componente Arte, mas com unidades temáticas diferentes: a primeira na unidade temática Música, com o objeto de conhecimento dos elementos da linguagem, enquanto que a segunda está na unidade temática Teatro, com o objeto de conhecimento os processos de criação que levam em consideração o "jogo cênico", conforme o exposto na BNCC (2018, p. 207).

Explorar e analisar elementos constitutivos da música (altura, intensidade, timbre, melodia, ritmo etc.), por meio de recursos tecnológicos (games e plataformas digitais), jogos, canções e práticas diversas de composição/criação, execução e apreciação musicais.

Experimentar a gestualidade e as construções corporais e vocais de maneira imaginativa na improvisação teatral e no jogo cênico.

Os jogos cênicos configuram-se como jogos de improvisação que são usados para auxiliar as expressões gestuais e vocais, utilizando situações cotidianas ou até mesmo simulando situações para organizar as ideias e a maneira de resolver os problemas da vida diária (SOCZEK, 2010). 
Já no que tange ao componente curricular Educação Física, de acordo com a BNCC, esse oferece diversas oportunidades para que crianças, jovens e adultos enriqueçam suas experiências durante toda a Educação Básica, ao terem acesso a um vasto universo cultural. Em relação a seus conteúdos, os mesmos estão organizados em unidades temáticas, nas quais as Brincadeiras e Jogos, Danças e Lutas estão organizadas em objetos de conhecimento conforme a ocorrência social dessas práticas corporais, das esferas sociais mais familiares (localidade e região) às menos familiares (esferas nacional e mundial). Em Ginásticas, a organização dos objetos de conhecimento se dá com base na diversidade dessas práticas e nas suas características. Em Esportes, a abordagem recai sobre a sua tipologia (modelo de classificação), enquanto que as Práticas Corporais de Aventura se estruturam nas vertentes urbana e na natureza (BRASIL, 2018).

Portanto, é possível verificar que, durante os anos inicias, o Jogo está presente neste componente curricular como uma unidade temática específica, juntamente com as Brincadeiras. Dentre algumas das habilidades a serem desenvolvidas no decorrer dos anos iniciais, no que diz respeito aos Jogos, pode-se destacar as seguintes presentes na BNCC (2018, p. 225 e 227).

Experimentar, fruir e recriar diferentes brincadeiras e jogos da cultura popular presentes no contexto comunitário e regional, reconhecendo e respeitando as diferenças individuais de desempenho dos colegas.

Explicar, por meio de múltiplas linguagens (corporal, visual, oral e escrita), as brincadeiras e os jogos populares do contexto comunitário e regional, reconhecendo e valorizando a importância desses jogos e brincadeiras para suas culturas de origem.

Experimentar e fruir brincadeiras e jogos populares do Brasil e do mundo, incluindo aqueles de matriz indígena e africana, e recriá-los, valorizando a importância desse patrimônio histórico cultural.

Recriar, individual e coletivamente, e experimentar, na escola e fora dela, brincadeiras e jogos populares do Brasil e do mundo, incluindo aqueles de matriz indígena e africana, e demais práticas corporais tematizadas na escola, adequando-as aos espaços públicos disponíveis.

A partir das habilidades acima apontadas, percebe-se a importância do Jogo apresentada no documento para a disciplina de Educação Física, ao traze-lo como uma unidade temática específica, com objeto de conhecimento e habilidades necessárias para o desenvolvimento dos alunos dessa faixa etária. Portanto, cabe ao professor planejar e utilizar estratégias para executar diferentes elementos do Jogo, identificando especificidades, possibilidades e conhecimentos que poderão ser explorados, sempre levando em consideração a singularidade e especificidade dos alunos, local e região. 
Já nos anos finais do Ensino Fundamental, o Jogo aparece somente no $6^{\circ}$ e $7^{\circ}$ anos como "jogos eletrônicos". Dessa forma, para esses anos de ensino, observa-se que o Jogo é direcionado a uma nova cultura, a da informática, em função da realidade e avanços tecnológicos. Isso pode ser constatado por meio das habilidades a serem desenvolvidas em relação aos jogos eletrônicos, como apontadas na BNCC (2018, p. 231):

Experimentar e fruir, na escola e fora dela, jogos eletrônicos diversos, valorizando e respeitando os sentidos e significados atribuídos a eles por diferentes grupos sociais e etários.

Identificar as transformações nas características dos jogos eletrônicos em função dos avanços das tecnologias e nas respectivas exigências corporais colocadas por esses diferentes tipos de jogos.

Como o último componente curricular da área das Linguagens, tem-se a Língua Inglesa, na qual possui caráter formativo ao inscrever a aprendizagem do inglês em uma perspectiva de educação linguística, consciente e crítica, com dimensões pedagógicas e políticas intrinsecamente ligadas (BRASIL, 2018). Esse componente está organizado por eixos, unidades temáticas, objetos de conhecimento e habilidades, se diferenciando dos demais por estar direcionado apenas aos anos finais do Ensino Fundamental.

Em relação ao Jogo, esse se faz presente na Língua Inglesa como uma habilidade a ser desenvolvida dentro da unidade temática "Estratégia de Leitura", com objeto de conhecimento denominado "Recursos de Persuasão", fazendo parte do eixo "Leitura". Isso pode ser identificado na BNCC (2018, p. 259) em uma das habilidades proposta no documento, ao destacar o "jogo de palavras" como meio para o ensino dos conteúdos dessa disciplina pedagógica:

Identificar recursos de persuasão (escolha e jogo de palavras, uso de cores e imagens, tamanho de letras), utilizados nos textos publicitários e de propaganda, como elementos de convencimento.

Segundo a BNCC, os conhecimentos matemáticos são necessários para todos os alunos da Educação Básica, seja por sua aplicação na sociedade contemporânea ou por sua potencialidade na formação de cidadãos críticos, cientes de suas responsabilidades sociais. Com isso, a área de Matemática, por sua vez, também possui competências específicas em articulação com as competências gerais da BNCC, garantindo o desenvolvimento dos alunos. A partir da leitura detalhada dessa área e de seu respectivo componente curricular - a própria Matemática, observa-se que o Jogo está ausente nas unidades temáticas, nos objetos de 
conhecimento e também nas habilidades propostas, tanto nos anos iniciais quanto nos anos finais do Ensino Fundamental.

Já na área de Ciências da Natureza - Ciências, a sociedade contemporânea está fortemente organizada com base no desenvolvimento científico e tecnológico. Por isso, ao longo do Ensino Fundamental, a área de Ciências da Natureza tem compromisso com o desenvolvimento do letramento científico que envolve a capacidade de compreender e interpretar o mundo (natural, social e tecnológico), mas também de transformá-lo com base nos aportes teóricos e processuais das ciências (BRASIL, 2018). O componente curricular de Ciências possui três unidades temáticas: Matéria e energia; Vida e evolução e Terra e universo, distribuídas para os anos iniciais e anos finais, com objetos de conhecimento e habilidades diferenciadas para cada faixa etária. No entanto, assim como na Matemática, identificou-se que o Jogo não está presente nesse respectivo componente curricular.

A área de Ciências Humanas, composta pelos componentes curriculares da Geografia e da História, é marcada pelas categorias básicas de tempo, espaço e movimento. Logo, não se pode deixar de valorizar também a crítica sistemática à ação humana, às relações sociais e de poder e, especialmente, à produção de conhecimentos e saberes, fruto de diferentes circunstâncias históricas e espaços geográficos (BRASIL, 2018). Como os demais componentes curriculares, a Geografia e a História também possuem competências específicas, com unidades temáticas, objetos de conhecimento e habilidades para cada faixa etária e etapa ao longo do Ensino Fundamental.

A partir da leitura realizada no componente curricular Geografia, constatou-se que o Jogo se faz presente na BNCC (2018, p. 369) para os anos iniciais $\left(1^{\circ}\right.$ ano $)$, com o objetivo de "Identificar semelhanças e diferenças entre jogos e brincadeiras de diferentes épocas e lugares". Salienta-se que o Jogo faz parte da unidade temática "O sujeito e seu lugar no mundo", tendo como objeto de conhecimento o modo de vida das crianças em diferentes lugares. Entretanto, destaca-se ainda que para as demais faixas etárias dos anos iniciais $\left(2^{\circ}, 3^{\circ}\right.$ e $4^{\circ}$ ), bem como para os anos finais, o Jogo encontra-se ausente como proposta/habilidade a ser desenvolvida nessas faixas etárias.

Já no que diz respeito à História, um de seus importantes objetivos no Ensino Fundamental é estimular a autonomia de pensamento e a capacidade de reconhecer que os indivíduos agem de acordo com a época e o lugar nos quais vivem, de modo a preservar ou transformar seus hábitos e condutas (BRASIL, 2018). Em relação ao Jogo, observa-se que o mesmo está presente nesse componente curricular da BNCC (2018 p. 405) ao situar-se em 
uma das habilidades a ser desenvolvida no $1^{\circ}$ ano dos anos iniciais: "Identificar semelhanças e diferenças entre jogos e brincadeiras atuais e de outras épocas e lugares". Nas demais faixas etárias dos anos iniciais e dos anos finais, mesmo possuindo procedimentos básicos para essas etapas, o Jogo não aparece nas propostas de unidades, objetos e habilidades do Ensino Fundamental, indo ao encontro da disciplina de Geografia.

A Constituição Federal de 1988 (artigo 210) e a LDB nº 9.394/1996 (artigo 33, alterado pela Lei $n^{\circ}$ 9.475/1997) estabeleceram os princípios e os fundamentos que devem alicerçar epistemologias e pedagogias do Ensino Religioso, cuja função educacional, enquanto parte integrante da formação básica do cidadão, é assegurar o respeito à diversidade cultural religiosa, sem proselitismos. Mais tarde, a Resolução CNE/CEB no 04/2010 e a Resolução CNE/CEB nº 07/2010 reconheceram o Ensino Religioso como uma das cinco áreas de conhecimento do Ensino Fundamental. Assim, a área de Ensino Religioso, por consequência, o componente curricular de Ensino Religioso, deve garantir aos alunos o desenvolvimento de algumas competências específicas dessa disciplina escolar. Por fim, no que tange ao Jogo, observa-se que ele está presente no Ensino Religioso ao longo do processo educacional durante o Ensino Fundamental, porém, como recurso metodológico para alcançar os próprios objetivos dessa disciplina escolar.

A partir destes resultados, é possível constatar que o Jogo, juntamente com seus conhecimentos e concepções, se faz presente principalmente na área das Linguagens - Língua Portuguesa, Arte, Educação Física e Língua Inglesa, mesmo que em apenas alguns anos do Ensino Fundamental. Sendo assim, para a Língua Portuguesa, o Jogo aparece como uma habilidade a ser desenvolvida, ao destacar: gêneros textuais: agendas, listas, bilhetes, diários, regras de jogos e brincadeiras; vídeo digital, programa infantil com instruções de montagem, de jogos e brincadeiras...; textos publicitários e de propagandas (cores, imagens, jogos de palavras...).

No componente curricular Arte, o Jogo se faz presente tanto como conteúdo quanto metodologia, como destacado em suas habilidades: elementos constitutivos da música por meio de jogos; utilização de brinquedos, brincadeiras e jogos; jogos eletrônicos; jogo cênico; jogos rítmicos (BRASIL, 2018).

No componente curricular Educação Física, o Jogo aparece como uma unidade temática, ou seja, como um conteúdo que tem fim e significado em si mesmo, abrangendo seu contexto comunitário, regional, nacional e mundial. Ainda é importante salientar que a Educação Física possui dez competências específicas que norteiam suas seis unidades 
temáticas, seus objetos de conhecimento e suas habilidades, estando o Jogo frequentemente presente nelas, desde os anos iniciais até a última faixa etária dos anos finais ( $9^{\circ}$ ano).

Como nas demais disciplinas pertencentes à área das Linguagens, na Língua Inglesa o Jogo também está presente no documento da BNCC, ao citar o "jogo de palavras" como forma metodológica de ensinar os conteúdos específicos dessa disciplina. $\mathrm{Na}$ área de Ciências Humanas, composta pela Geografia e História, ao considerar suas categorias de ensino, o Jogo se faz presente em algum momento no decorrer do Ensino Fundamental em ambos componentes curriculares, ao se remeter à presença dos "jogos em diferentes épocas e lugares". No entanto, na Matemática e nas Ciências, constata-se a ausência do Jogo como conteúdo ou até mesmo como meio para ensinar seus conteúdos específicos. Já no Ensino Religioso, ele caracteriza-se apenas como um meio (metodologia) para alcançar os objetivos da própria disciplina.

\section{CONSIDERAÇÕES FINAIS}

O Jogo consiste em um conhecimento composto por vários significados $\mathrm{e}$ características apresentadas em diferentes dimensões teóricas, metodológicas e pedagógicas que vêm sendo discutidas e conceituadas por diversos autores da área da Educação. Por isso, o presente estudo teve por intuito identificar o sentido do Jogo disposto na Base Nacional Comum Curricular, na Educação Infantil e nos distintos componentes curriculares do Ensino Fundamental - anos iniciais e anos finais.

Logo, constatou-se que no documento da BNCC, os conhecimentos e concepções de Jogo variam por etapa e componente curricular. Assim, na Educação Infantil, essa manifestação cultural possui sentido com fim em si mesmo, ao apresentar, como elementos que permeiam toda essa etapa de ensino, eixos estruturantes e direitos de aprendizagem e desenvolvimento das crianças que fazem menção, diretamente, aos diferentes Jogos e brincadeiras. Por outro lado, durante o Ensino Fundamental, ao se apresentar como um conteúdo específico, o mesmo passa por um processo em que essa essência vai se perdendo, como é a caso da Educação Física, em que os esportes e os jogos eletrônicos se sobressaem ao se aproximar do Ensino Médio. Além disso, ao se fazer presente nas demais disciplinas, o Jogo ainda é, na maioria das vezes, tido apenas com um meio para ensinar e articular os conteúdos específicos de cada componente curricular.

A partir dos resultados desta pesquisa, pode-se afirmar que a cultura do Jogo, enquanto construção social, precisa ser experienciada e vivenciada em um determinado tempo 


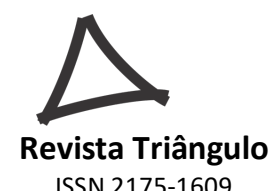

ISSN 2175-1609

e espaço, levando em consideração sua importância no desenvolvimento do indivíduo durante a infância e a adolescência, ancorado por documentos de caráter educacional como a BNCC, na qual determina, norteia e orienta as práticas pedagógicas da educação brasileira, almejando a qualidade educacional. Através de Jogos, as crianças e jovens expressam e refletem o que vivenciam, uma vez que essas práticas derivam de situações da vida social e cultural que os mesmos estão envolvidos, proporcionando o ensino e a construção de aprendizagem, individual e coletivamente.

Por fim, esta pesquisa também tem por intuito possibilitar a apropriação desses conhecimentos por parte de futuros pesquisadores e leitores acerca das concepções de Jogo, bem como sua importância no contexto educacional, permitindo novas reflexões e possibilidades de pesquisas, englobando, também, o Ensino Médio, não comtemplado por este estudo.

\section{REFERÊNCIAS}

BRASIL. Constituição da República Federativa do Brasil. Brasília: Senado, 1988.

Lei de Diretrizes e Bases da Educação Nacional. Brasília: DF, 1996.

. Ministério da Educação. Base Nacional Comum Curricular. Brasília, 2018.

Disponível em: <http://basenacionalcomum.mec.gov.br/a-base>. Acesso em: 18 set. 2018.

. Ministério da Educação. Base Nacional Comum Curricular. Proposta preliminar. Segunda versão. Brasília, 2016. Disponível em:

$<$ http://portal.mec.gov.br/dmdocuments/rceb007_10.pdf $>$. Acesso em: 18 set. 2018.

. Ministério da Educação. Base Nacional Comum Curricular. Proposta preliminar.

Terceira versão. Brasília, 2017. Disponível em:

$<$ https://web.moderna.com.br/documents/3901628/0/BNCC+-

+ Material + para + o+professor/01f4c4f9-7774-4e0d-bedb-565635b3294c $>$. Acesso em: 11 set. 2018 .

HUIZINGA, J. (Org.) Homo Ludens: o jogo como elemento da cultura. 5. ed. São Paulo: Perspectiva, 2007.

KUNZ, E. (Org.) Brincar e Se-movimentar: tempos e espaços da vida da criança. Ijuí: Unijuí, 2017.

PIMENTEL, A. O método da análise documental: seu uso numa pesquisa historiográfica.

Cadernos de Pesquisa, São Paulo, n. 114, p. 179-195, nov. 2001. ISSN 0100- 1574.

Disponível em: $<$ http://www.scielo.br/pdf/cp/n114/a08n114.pdf $>$. Acesso em: 21 mar. 2018. 


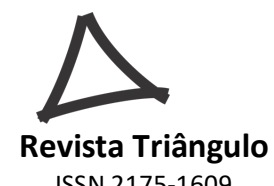

ISSN 2175-1609

RICHARDSON, R. J. (Org.) Pesquisa social: métodos e técnicas. 3. ed. São Paulo: Atlas, 1999.

SÁ-SILVA, J. R.; ALMEIDA, C. D.; GUINDANI, J. F. Pesquisa Documental: pistas teóricas e metodológicas. Revista Brasileira de História \& Ciências Sociais, Rio Grande, Ano I, n. 1, p. 01-15, jul. 2009. ISSN 2175-3423. Disponível em:

$<$ https://www.rbhcs.com/rbhcs/article/view/6>. Acesso em: 13 maio. 2018.

SILVA, W. R.; GUIMARÃES, E. V.; MEDEIROS, I. A. Construção de objetos de conhecimento para aulas de Língua Portuguesa na abordagem do letramento científico.

Revista Brasileira de Linguística Aplicada, Belo Horizonte, v. 18, n. 1, p. 159-191, jan./mar. 2018. ISSN 1984-6398. Disponível em: $<$ http://www.scielo.br/pdf/rbla/v18n1/19846398-rbla-18-01-159.pdf>. Acesso em: 16 ago. 2018. doi:http://dx.doi.org/10.1590/19846398201812288.

SOCZEK M. E. Os Jogos Cênicos de improvisação e a Escola. out. 2010. Disponível em: $<$ http://educa29.blogspot.com/2010/10/os-jogos-cenicos-de-improvisacao-e.html $>$. Acesso em: 28 maio. 2018.

TEZANI, T. C. R. O jogo e os processos de aprendizagem e desenvolvimento: aspectos cognitivos e afetivos. Educação em Revista, Marília, v. 7, n. 1-2, p. 1-16, 2006. ISSN: 15187926. Disponível em: <file://C:/Users/Raquel/Downloads/603-Texto\%20do\%20artigo-21051-10-20110505.pdf>. Acesso em: 17 abr. 2018.

\begin{tabular}{|l|l|}
\hline & Recebido em: 20 Dez. 2018 \\
\cline { 2 - 2 } & Aprovado em: 29 Abr. 2019 \\
\hline
\end{tabular}

